\title{
Hubungan Lingkungan Fisik Rumah dengan Kejadian Pneumonia pada Balita di Wilayah Kerja Puskesmas Plumbon
}

\section{The Relationship Between the Physical Home Environment with the Incidence of Pneumonia in Toddlers in the Working Area of the Plumbon Health Center}

\author{
Hairil Akbar', Hamzah B ${ }^{1}$, St. Rahmawati Hamzah², Matius Paundanan³, La Ode Reskiaddin ${ }^{4}$ \\ ${ }^{1}$ Program Studi Kesehatan Masyarakat Institut Kesehatan dan Teknologi Graha Medika, Kotamobagu \\ ${ }^{2}$ Program Studi DIII Kebidanan Institut Kesehatan dan Teknologi Graha Medika, Kotamobagu \\ ${ }^{3}$ Program Studi Kesehatan Masyarakat STIK Indonesia Jaya, Palu \\ ${ }^{4}$ Program Studi Ilmu Kesehatan Masyarakat, Universitas Jambi, Jambi
}

\begin{abstract}
Abstrak
Pneumonia merupakan salah satu penyakit infeksi saluran pernapasan akut bagian bawah yang menjadi penyebab utama morbiditas dan mortalitas anak berusia dibawah lima tahun terutama di negara yang sedang berkembang. Tujuan penelitian ini untuk mengetahui hubungan jenis lantai rumah dan jenis dinding rumah dengan kejadian pneumonia pada balita di wilayah kerja Puskesmas Plumbon. Jenis penelitian yang digunakan observasional analitik dengan rancangan cross sectional dengan jumlah sampel sebanyak 43 responden. Teknik penarikan sampel yang digunakan adalah Acidental Sampling. Data dikumpulkan dengan wawancara langsung kepada responden dan dianalisis secara univariat dan bivariat dengan menggunakan uji chi square. Hasil penelitian menunjukkan bahwa terdapat $62,8 \%$ responden yang mempunyai balita menderita pneumonia, $44,2 \%$ responden yang memiliki jenis lantai rumah yang tidak memenuhi syarat kesehatan dan terdapat $51,2 \%$ resespon yang memiliki jenis dinding rumah yang tidak memenuhi syarat kesehatan. Hasil uji statistik diperoleh ada hubungan antara jenis lantai rumah dengan kejadian pneumonia pada balita $(\mathrm{p}=0,010<0,05)$ dan ada hubungan antara jenis dinding rumah dengan kejadian pneumonia pada balita $(\mathrm{p}=0,008<0,05)$ di wilayah kerja Puskesmas Plumbon. Kesimpulan dari dua variabel ada hubungan antara jenis lantai rumah dan jenis dinding rumah dengan kejadian pneumonia pada balita di wilayah kerja Puskesmas Plumbon.
\end{abstract}

Kata Kunci: Lantai, Dinding, Pneumonia, Balita

\begin{abstract}
Pneumonia is one of the acute lower respiratory tract infections which is a major cause of morbidity and mortality in toddlers, especially in developing countries. The purpose of this study was to determine the relationship between the type of floor snd the type of wall of the house with the incidence of pneumonia in toddlers in the working area of Plumbon Health Center. This study applied an analytic observational study design with a cross sectional approach. The total sample of the study was 43 respondents taken using accidental sampling technique. Data were collected by direct interviews with respondents and analyzed univariately and bivariately using chi square test. The results showed that there were $62.8 \%$ of respondents who had a toddler, suffering from pneumonia, $44.2 \%$ of respondents employed type of house floor that did not fit health requirements and $51.2 \%$ of respondents had a type of house wall that did not fit health requirements. The results of statistical tests showed that there was a relationship between the type of floor of the house and the incidence of pneumonia in toddlers $(p=0.010<0.05)$ and there was a relationship between the type of wall of the house and the incidence of pneumonia in toddlers $(p=0.008<0.05)$ in the working area of the Plumbon Health Center. Therefore, it can be inferred that from the two variables, there was a relationship between the type of floor of the house and the type of wall of the house with the incidence of pneumonia in toddlers in the working area of Plumbon Health Center.
\end{abstract}

Keywords: Floor, Wall, Pneumonia, Toddler

Korespondensi : Hairil Akbar

Email : hairil.akbarepid@gmail.com 


\section{PENDAHULUN}

Infeksi Saluran Pernafasan Akut (ISPA) adalah infeksi akut yang berlangsung kurang dari 14 hari disebabkan oleh mikroorganisme di saluran pernafasan mulai dari hidung, telinga, laring, trachea, bronchus, bronkhiolus, sampai dengan paru-paru (1). Pneumonia merupakan salah satu penyakit infeksi saluran pernapasan akut bagian bawah yang menjadi penyebab utama morbiditas dan mortalitas anak berusia dibawah lima tahun terutama di negara yang sedang berkembang. Pneumonia pada balita dapat menyebabkan balita yang meninggal sekitar 2.500 anak setiap harinya. Secara statistik, balita yang meninggal di seluruh dunia akibat pneumonia pada tahun 2015 adalah $16 \%$ dari semua kematian pada balita yaitu sebanyak 920.136 anak (2).

World Health Organization (WHO) pada tahun 2011 menyebutkan bahwa seperlima dari kematian bayi dan balita terutama di negara-negara berkembang disebabkan oleh pneumonia, melebihi penyakit-penyakit lain seperti campak, malaria, serta AIDS. Setiap tahunnya terdapat sebanyak 2 juta bayi yang meninggal karena pneumonia, 5.500 anak meninggal setiap hari atau 4 bayi meninggal setiap satu menit. Pada tahun 2010 pneumonia merupakan pembunuh terbesar bagi balita di seluruh dunia dengan angka 18\% dan diikuti oleh diare dengan $11 \%$ (3). Berdasarkan data laporan rutin Subdit ISPA, didapatkan insiden (per 1000 balita) di Indonesia sebesar 20,06\% hampir sama dengan data tahun sebelumnya $20,56 \%$. Salah satu upaya yang dilakukan untuk mengendalikan penyakit ini yaitu dengan meningkatkan penemuan pneumonia pada balita. Perkiraan kasus pneumonia secara nasional sebesar 3,55\% namun angka perkiraan kasus pneumonia di masing-masing provinsi menggunakan angka yang berbeda-beda sesuai angka yang telah ditetapkan (4).

Berdasarkan data dari Ditjen P2P, Kemenkes RI jumlah kasus pneumonia di Jawa Barat pada balita umur < 1 tahun sebanyak 48.397 kasus dan balita umur 1-4 tahun sebanyak 82.985 kasus. Total keseluruhan kasus pneumonia pada balita tahun 2016 sebanyak 131.382. Jumlah kematian balita karena pneumonia di Jawa Barat umur $<1$ tahun sebesar 14 kasus dan umur 1-4 tahun sebesar 4 kasus dengan case fatality rate sebesar 0,03 (4).

Faktor risiko kejadian pneumonia terbagi atas dua kelompok besar yaitu faktor instrinsik dan faktor ekstrinsik. Faktor instrinsik meliputi umur, jenis kelamin, status gizi, berat badan lahir rendah, status imunisasi, pemberian ASI, dan pemberian vitamin A. Faktor ekstrinsik meliputi kepadatan tempat tinggal, tipe rumah, ventilasi, jenis lantai, pencahayaan, kepadatan hunian, kelembaban, jenis bahan bakar, penghasilan keluarga serta faktor ibu baik pendidikan, umur ibu, maupun pengetahuan ibu dan keberadaan keluarga yang merokok (5).

Data laporan Puskesmas Plumbon Kecamatan Indramayu, Jawa Barat menunjukkan bahwa jumlah kasus kategori penyakit ISPA pnemonia pada tahun 2017 cukup tinggi sebanyak 505 kasus. Angka penemuan kasus pneumonia masih cukup tinggi di wilayah kerja Puskesmas Plumbon karena faktor sanitasi lingkungan yang kurang baik misalnya faktor lingkungan fisik rumah yang belum memenuhi syarat kesehatan (6).

Menurut Khasanah dkk (2016) di Wilayah Kerja Puskesmas Puring Kabupaten Kebumen menemukan bahwa ada hubungan antara jenis lantai dengan kejadian pneumonia pada balita $(\mathrm{p}=0,015)$. Besarnya risiko menderita pneumonia dapat dilihat dari nilai $\mathrm{OR}=3,4$ dengan $95 \% \mathrm{CI}=1,355-8,531$ yang artinya anak balita yang tinggal di rumah dengan jenis lantai tidak memenuhi syarat memiliki risiko terkena pneumonia sebesar 3,4 kali lebih besar dibandingkan dengan anak balita yang tinggal di rumah dengan jenis lantai memenuhi syarat 
(7).

Penelitian lain yang dilakukan di Gampong Blang Muko Kecamatan Kuala Kabupaten Nagan Raya tahun 2016 di dapatkan nilai $p$ value $0,000<0,05$. Dari hasil tersebut juga terdapat nilai odds ratio (OR) yaitu 2,618 artinya bahwa seseorang yang mempunyai dinding rumah kurang baik memiliki resiko akan mengalami pneumonia 2,618 kali lebih besar di bandingkan dengan seseorang yang dinding rumahnya tidak memenuhi syarat kesehatan (8).

Dalam rangka program pencegahan penyakit saluran pernafasan akut dititik beratkan pada lingkungan dan peningkamutu kualitas hidup masyarakat, melalui peningkatan sosial ekonomi pelayanan kesehatan dan pemerataan pendidikan. Terpeliharanya usaha tersebut tentunya akan menurunkan kejadian penularan penyakit infeksi lainnya, guna menciptakan kesehatan yang optimal dan hidup produktif baik sosial dan ekonomis (9).

\section{METODE}

Penelitian ini menggunakan metode analitik dengan melakukan pendekatan Cross Sectional Study. Untuk mengetahui hubungan jenis lantai rumah dan jenis dinding rumah dengan kejadian pneumonia di wilayah kerja Puskesmas Plumbon. Penelitian ini berlokasi di wilayah kerja Puskesmas Plambon Kabupaten Indramayu. Populasi dalam penelitian ini adalah seluruh ibu yang memiliki balita yang berkunjung di wilayah kerja Puskesmas Plumbon sebanyak 208. Sampel pada penelitian ini adalah pasien yang menderita dan tidak menderita penyakit pneumonia pada balita yang sedang melakukan pemeriksaan di Puskesmas Plumbon Kabupaten Indramayu sebanyak 43 responden. Besar sampel dihitung dengan menggunakan rumus estimasi proporsi Lemeshow.

Pengambilan sampel dengan cara Accidental sampling yaitu pengambilan sampel secara kebetulan namun tetap sesuai tujuan penelitian dan bukan random. Data dikumpulkan dengan wawancara langsung menggunakan kuesioner dan lembar observasi, Data selanjutnya dianalisis secara univariat dan bivariat dengan menggunakan uji chi square $\alpha=0,05$.

\section{HASIL PENELITIAN}

Analisis univariat digunakan untuk mendeskripsikan data yang dilakukan pada tiap variabel dari hasil penelitian. Data yang terkumpul disajikan dalam bentuk table distribusi frekuensi. Berdasarkan tabel 1 dapat diketahui bahwa dari 43 responden mayoritas responden mempunyai jenis lantai rumah yang memenuhi syarat berjumlah 24 responden $(55,8 \%)$ dan minoritas tidak memenuhi syarat berjumlah 19 responden $(44,2 \%)$. Dapat diketahui bahwa dari 43 responden mayoritas responden mempunyai jenis dinding rumah yang tidak memenuhi syarat berjumlah 22 responden $(51,2 \%)$ dan minoritas memenuhi syarat berjumlah 21 responden $(48,8 \%)$. Dapat diketahui dari 43 responden mayoritas responden mempunyai balita pneumonia berjumlah 27 responden $(62,8 \%)$ dan minoritas balita tidak pneumonia berjumlah 16 responden $(37,2 \%)$. 


\section{Tabel 1. Distribusi Frekuensi Responden Berdasarkan Jenis Lantai Rumah dan Jenis Dinding Rumah dengan Kejadian Pneumonia pada Balita di Wilayah Kerja Puskesmas Plumbon}

\begin{tabular}{|c|c|c|}
\hline Jenis Lantai Rumah & $\mathbf{n}$ & $\%$ \\
\hline Memenuhi Syarat & 24 & 55,8 \\
\hline Tidak Memenuhi Syarat & 19 & 44,2 \\
\hline \multicolumn{3}{|l|}{ Jenis Dinding Rumah } \\
\hline Memenuhi Syarat & 21 & 48,8 \\
\hline Tidak Memenuhi Syarat & 22 & 51,2 \\
\hline \multicolumn{3}{|l|}{ Kejadian Pneumonia } \\
\hline Tidak Pneumonia & 16 & 37,2 \\
\hline Pneumonia & 27 & 62,8 \\
\hline Jumlah & 43 & 100 \\
\hline
\end{tabular}

Sumber: Data Sekunder

Analisis bivariat adalah untuk melihat hubungan kemaknaan antara variabel independen yaitu jenis lantai rumah dan jenis dinding rumah dengan variabel dependen yaitu kejadian pneumonia pada balita. Uji statistik yang digunakan adalah uji Chi-square dimana tingkat kemaknaannya adalah $95 \%(0,05)$.

Tabel 2. Hubungan Jenis Lantai Rumah dengan Kejadian Pneummonia pada Balita di Wilayah Kerja Puskesmas Plambon

\begin{tabular}{|c|c|c|c|c|c|c|c|}
\hline \multirow{3}{*}{$\begin{array}{c}\text { Jenis Lantai } \\
\text { Rumah }\end{array}$} & \multicolumn{4}{|c|}{ Kejadian Pneumonia } & \multirow{2}{*}{\multicolumn{2}{|c|}{ Total }} & \multirow[t]{3}{*}{$p$-value } \\
\hline & \multicolumn{2}{|c|}{ Tidak Pneumonia } & \multicolumn{2}{|c|}{ Pneumonia } & & & \\
\hline & $\mathbf{f}$ & $\%$ & $\mathbf{f}$ & $\%$ & $\mathbf{n}$ & $\%$ & \\
\hline Memenuhi Syarat & 13 & 54,2 & 11 & 45,8 & 24 & 100 & 0,010 \\
\hline Tidak Memenuhi & 3 & 15,8 & 16 & 84,2 & 19 & 100 & \\
\hline \multicolumn{7}{|l|}{ Syarat } & \\
\hline Jumlah & 16 & 37,2 & 27 & 62,8 & 27 & 100 & \\
\hline
\end{tabular}

Sumber: Data Sekunder

Berdasarkan tabel 2 menunjukkan bahwa dari 24 responden yang mempunyai jenis lantai rumah yang memenuhi syarat terdapat 13 responden $(54,2 \%)$ yang mempunyai balita tidak menderita pneumonia dan terdapat 11 responden $(45,8 \%)$ yang mempunyai balita menderita pneumonia, sedangkan dari 19 responden yang mempunyai jenis lantai rumah yang tidak memenuhi syarat terdapat 16 responden $(84,2 \%)$ yang mempunyai balita menderita pneumonia dan terdapat 3 responden $(15,8 \%)$ yang mempunyai balita tidak menderita pneumonia.

Hasil uji chi square antara variabel jenis lantai rumah dengan kejadian pneumonia pada balita diperoleh nilai $\mathrm{p}$ value $=0,010(\mathrm{p}<0,05)$ maka (Ho ditolak) yang artinya ada hubungan jenis lantai rumah dengan kejadian pneumonia pada balita di wilayah kerja Puskesmas Plumbon Kabupaten Indramayu.

Berdasarkan tabel 3 menunjukkan bahwa dari 21 responden yang mempunyai jenis dinding rumah yang memenuhi syarat terdapat 12 responden $(57,1 \%)$ yang mempunyai balita 
tidak menderita pneumonia dan terdapat 9 responden $(42,9 \%)$ yang mempunyai balita menderita pneumonia, sedangkan dari 22 responden yang mempunyai jenis dinding rumah yang tidak memenuhi syarat terdapat 18 responden $(81,8 \%)$ yang mempunyai balita menderita pneumonia dan terdapat 4 responden $(18,2 \%)$ yang mempunyai balita tidak menderita pneumonia.

Tabel 3. Hubungan Jenis Dinding Rumah dengan Kejadian Pneummonia pada Balita di Wilayah Kerja Puskesmas Plambon

\begin{tabular}{lccccccc}
\hline Dinding Rumah & \multicolumn{9}{c}{ Kejadian Pneumonia } & \multicolumn{2}{c}{ Total } & p-value \\
\cline { 2 - 7 } & \multicolumn{1}{c}{ Tidak Pneumonia } & Pneumonia & & \\
\cline { 2 - 7 } & $\mathbf{f}$ & $\boldsymbol{\%}$ & $\mathbf{f}$ & $\mathbf{\%}$ & $\mathbf{n}$ & $\boldsymbol{\%}$ & \\
\hline Memenuhi Syarat & 12 & 57,1 & 9 & 42,9 & 21 & 100 & 0,008 \\
Tidak Memenuhi & 4 & 18,2 & 18 & 81,8 & 22 & 100 & \\
Syarat & & & & & & & \\
\hline \multicolumn{1}{c}{ Jumlah } & 16 & 37,2 & 27 & 62,8 & 43 & 100 & \\
\hline
\end{tabular}

Sumber: Data Sekunder

Hasil uji chi square antara variabel jenis dinding rumah dengan kejadian pneumonia pada balita diperoleh nilai $\mathrm{p}$ value $=0,008(\mathrm{p}<0,05)$ maka (Ho ditolak) yang artinya ada hubungan jenis dinding rumah dengan kejadian pneumonia pada balita di wilayah kerja Puskesmas Plumbon.

\section{PEMBAHASAN}

Hasil analisis pada tabel 2 menunjukkan bahwa dari 24 responden yang mempunyai jenis lantai rumah yang memenuhi syarat terdapat 11 responden $(45,8 \%)$ yang mempunyai balita menderita pneumonia, sedangkan dari 19 responden yang mempunyai jenis lantai rumah yang tidak memenuhi syarat terdapat 16 responden $(84,2 \%)$ yang mempunyai balita menderita pneumonia. Hal ini disebabkan karena berdasarkan hasil pengamatan pada rumah responden masih ada rumah responden yang terbuat dari tanah kemudian diberikan terpal plastik sebagai pelindung dan rumah dengan lantai yang di beton/cor.

Menurut responden jika pada musim kemarau lantai rumah akan sangat berdebu hal ini akan menganggu sistem pernapasan setiap penghuni rumah khususnya balita dan jika musim penghujan kondisi lantai rumah akan sangat terasa lembab. Keadaan ini menjadi salah satu bentuk terjadinya pulusi udara dalam rumah (indoor air pollution). Debu dalam udara apabila terhirup akan menempel pada saluran nafas bagian bawah sehingga menimbulkan iritasi pada saluran pernafasan, akibatnya balita kesulitan bernafas (10).

Hasil analisis bivariat diperoleh hasil uji statistik dengan nilai $p$ value $=0,010(\mathrm{p}<0,05)$ maka dapat disimpulkan bahwa secara statistik ada hubungan jenis lantai rumah dengan kejadian pneumonia pada balita di wilayah kerja Puskesmas Plumbon Kabupaten Indramayu. Penelitian ini sejalan dengan penelitian yang dilakukan di Kelurahan Serengsem Kecamatan Panjang Wilayah Kerja Puskesmas Panjang Bandar Lampung dengan jumlah sampel sebanyak 214 orang menemukan bahwa ada hubungan yang signifikan antara jenis lantai ( $p$ value = 0,003) dengan kejadian pneumonia pada anak balita (11). 
Selanjutnya penelitian yang dilakukan di wilayah kerja Puskesmas Puring Kabupaten Kebumen menunjukkan ada hubungan antara jenis lantai dengan kejadian pneumonia pada balita ( $\mathrm{p}=0,015)$. Besarnya risiko menderita pneumonia dapat dilihat dari nilai $\mathrm{OR}=3,4$ dengan $95 \% \mathrm{CI}=1,355-8,531$ yang artinya anak balita yang tinggal di rumah dengan jenis lantai tidak memenuhi syarat memiliki risiko terkena pneumonia sebesar 3,4 kali lebih besar dibandingkan dengan anak balita yang tinggal di rumah dengan jenis lantai memenuhi syarat (7).

Penelitian lain yang di Desa Karatung I Kecamatan Manganitu Kabupaten Kepulauan Sangihe dengan jumlah sampel sebanyak 67 responden menemukan bahwa ada hubungan yang bermakna antara kondisi lantai rumah yang tidak memenuhi syarat dengan kejadian pneumonia pada balita $(\mathrm{p}=0,008)(12)$.

Rumah yang sehat adalah jika memiliki dinding yang terbuat dari conblock atau batu bata dan telah diplaster. Hal ini difungsikan untuk memberikan perlindungan penghuninya dari berbagai kondisi lingkungan luar rumah yang dapat membahayakan kesehatan dan keselamatan, salah satunya adalah kondisi udara luar rumah yang mengalami pencemaran seperti gas-gas beracun dari alam ataupun aktivitas manusia.

Kementrian Kesehatan melalui Ditjen P2PL menejlaskan bahwa ruangan di dalam rumah akan menjadi lebih panas dan lembab jika lantai rumah masih terbuat dari tanah, bahkan kandungan pencemar dari bahan bangunan rumah juga kana mengalami peningkatan karena terjadi penguapan di dalam ruangan akibat suhu panas yang meningkat. Sel-sel bakteri termasuk Pneumococus akan mengalami pertumbuhan yang cepat pada kelembaban yang tinggi karena kandungan uap air di udara cukup tinggi, sehingga kondisi ini sangat kondusif bagi pertumbuhan dan kelangsungan hidup agent penyakit ISPA pneumonia tersebut (4).

Hasil analisis pada tabel 3 menunjukkan bahwa dari 21 responden yang mempunyai jenis dinding rumah yang memenuhi syarat terdapat 9 responden $(42,9 \%)$ yang mempunyai balita menderita pneumonia, sedangkan dari 22 responden yang mempunyai jenis dinding rumah yang tidak memenuhi syarat terdapat 18 responden $(81,8 \%)$ yang mempunyai balita menderita pneumonia. Adapun pada penelitian ini didapatkan bahwa rumah responden masih banyak yang belum memenuhi syarat, misalnya jenis dinding rumah terbuat dari kayu dan anyaman bambu serta belum diplaster yang memudahkan debu menempel. Selain itu, bahan bangunan rumah tidak boleh terbuat dari bahan yang dapat melepaskan zat-zat yang dapat membahayakan kesehatan, sementara rumah responden yang ditemukan pada saat penelitian masih ada yang terbuat dari kayu dan anyaman bambu.

Hasil analisis bivariat diperoleh hasil uji statistik dengan nilai $p$ value $=0,008(\mathrm{p}<0,05)$ maka dapat disimpulkan bahwa secara statistik ada hubungan jenis dinding rumah dengan kejadian pneumonia pada balita di wilayah kerja Puskesmas Plumbon Kabupaten Indramayu. Penelitian ini sejalan dengan penelitian yang di wilayah kerja Puskesmas Pati I Kabupaten Pati dengan sampel anak umur 12-59 bulan yang menderita pneumonia menemukan bahwa ada hubungan jenis dinding rumah dengan kejadian pneumonia pada balita $(\mathrm{p}=0,053 ; \mathrm{OR}=5,375)$, balita yang tinggal di rumah yang dinding tidak memenuhi syarat mempunyai risiko 5,375 kali lebih besar menderita pneuomonia dibandingkan dengan balita yang tinggal di rumah dengan dinding yang memenuhi syarat (13).

Penelitian lain yang dilakukan ada hubungan yang signifikan antara jenis dinding dengan kejadian pneumonia pada bayi dengan nilai $\mathrm{p}=0,004$ dan $\mathrm{OR}=6,62$ dengan CI 95\% $=1,79$ 24,57. Sehingga jenis dinding rumah tidak permanen menjadi faktor risiko terhadap kejadian 
pneumonia pada bayi. Dari nilai odds ratio dapat diketahui bahwa bayi yang tinggal di rumah dengan dinding tidak permanen mempunyai risiko menderita pneumonia 6,62 kali lebih besar bila dibanding dengan bayi yang tinggal di rumah dengan dinding permanen (14).

Diketahui bahwa dinding merupakan komponen rumah yang mampu mencegah panas pada siang hari dan menahan panas pada malam hari sehingga menyebabkan kondisi suhu maupun kelembaban dalam rumah relatif sama. Dinding menjadi media bagi proses rising damp (kelembaban yang naik dari tanah) yang merupakan salah satu faktor penyebab kelembaban dalam rumah. Kondisi lembab ini akan menjadi prakondisi pertumbuhan kuman maupun bakteri patogen yang dapat menimbulkan penyakit bagi penghuninya.

Kondisi rumah dan lingkungan dapat mempengaruhi kejadian penyakit pneumonia. Konstruksi rumah dan lingkungan yang tidak memenuhi syarat kesehatan merupakan faktor risiko penularan berbagai jenis penyakit berbasis lingkungan, salah satunya pneumonia (15).

\section{KESIMPULAN DAN SARAN}

Berdasarkan hasil penelitian maka dapat disimpulkan ada hubungan antara jenis lantai rumah dengan kejadian pneumonia pada balita di wilayah kerja Puskesmas Plumbon Kabupaten Indramayu dengan nilai $\mathrm{p}=0,010<0,05$ dan ada hubungan antara jenis lantai rumah dengan kejadian pneumonia pada balita di wilayah kerja Puskesmas Plumbon Kabupaten Indramayu dengan nilai $\mathrm{p}=0,008<0,05$.

Kepada petugas kesehatan agar dapat meningkatkan penyuluhan kesehatan tentang penyakit pneumonia. Selain itu, menghimbau kepada masyarakat agar memperhatikan kondisi rumah dan membina masyarakat agar membuat rumah menjadi rumah sehat. Bagi peneliti selanjutnya, agar hasil penelitian ini dapat digunakan sebagai salah satu data dasar untuk acuan dan pedoman dalam melakukan penelitian selanjutnya.

\section{DAFTAR PUSTAKA}

1. Eko Budi Santoso. HA. Faktor yang Berhubungan dengan Kejadian ISPA pada Balita di Wilayah Kerja Puskesmas Juntinyuat. HIBUALAMO Seri Ilmu-ilmu Alam dan Kesehat. 2018;2(2).

2. Rigustia R, Zeffira L, Vani AT. Faktor Risiko yang Berhubungan dengan Kejadian Pneumonia pada Balita di Puskesmas Ikur Koto Kota Padang. Heal Med J. 2019;1(1):229.

3. Liu L, Oza S, Hogan D, Perin J, Rudan I, Lawn JE, et al. Global, regional, and national causes of child mortality in 2000-13, with projections to inform post-2015 priorities: an updated systematic analysis. Lancet. 2015;385(9966):430-40.

4. Kemenkes RI. Profil Kesehatan Indonesia Tahun 2018. Jakarta: Kementrian Kesehatan RI; 2019.

5. Rachmawati DA. Faktor Risiko yang berhubungan dengan Kejadian Pneumonia pada Balita Umur 12-48 Bulan di Wilayah KerjaPuskesmas Mijen Kota Semarang. J Kesehat Masy Univ Diponegoro. 2013;2(1):18842.

6. Puskesmas Plumbon. Profil Kesehatan Puskesmas Plumbon Tahun 2018. Indramayu: Puskesmas Plumbon; 2018.

7. Khasanah M, Suhartono S, Dharminto D. Hubungan Kondisi Lingkungan dalam Rumah dengan Kejadian Pneumonia pada Balita di Wilayah Kerja Puskesmas Puring Kabupaten 
Kebumen. J Kesehat Masy. 2016;4(5):27-34.

8. Safrizal S. Hubungan Ventilasi, Lantai, Dinding, dan Atap dengan Kejadian Ispa Pada Balita Di Blang Muko. In: Prosiding Seminar Nasional IKAKESMADA "Peran Tenaga Kesehatan dalam Pelaksanaan SDGs." Fakultas Kesehatan Masyarakat Universitas Ahmad Dahlan; 2017. p. 41-8.

9. Sudirman, Muzayana, Saleh SNH, Akbar H. Hubungan ventilasi rumah dan jenis bahan bakar memasak dengan kejadian ISPA pada balita di wilayah kerja Puskesmas Juntinyuat. Mppki. 2020;3(3):187-91.

10. Sugihartono S, Rahmatullah $\mathrm{P}$, Nurjazuli N. Analisis faktor risiko kejadian pneumonia pada balita di wilayah kerja Puskesmas Sidorejo Kota Pagar Alam. J Kesehat Lingkung Indones. 2012;11(1):82-6.

11. Suryawan B. Hubungan Komponen Rumah Sehat Dengan Kejadian Pneumonia Pada Anak Balita Di Kelurahan Serengsem Kecamatan Panjang Wilayah Kerja Puskesmas Panjang Bandar Lampung Tahun 2013. J Med Malahayati. 2015;2(2):74-80.

12. Katiandagho D, Nidawati N. Hubungan Kodisi Fisik Rumah dengan Kejadian Pneumonia Pada Balita di Desa Karatung I Kecamatan Manganitu Kabupaten Kepulauan Sangihe. Hig J Kesehat Lingkung. 2018;4(2):74-81.

13. Sari EL. Hubungan antara kondisi lingkungan fisik rumah dengan kejadian Pneumonia pada balita di wilayah kerja Puskesmas Pati I Kabupaten Pati. Diponegoro University; 2013.

14. Juni M, Nurjazuli N, Suhartono S. Hubungan Faktor Kualitas Lingkungan Rumah Dengan Kejadian Pneumonia Pada Bayi di Wilayah Kerja Puskesmas Banjarmangu 1 Kabupaten Banjarnegara. J Kesehat Lingkung Indones. 2016;15(1):6-13.

15. Pramudiyani NA, Prameswari GN. Hubungan antara sanitasi rumah dan perilaku dengan Kejadian pneumonia balita. KEMAS J Kesehat Masy. 2011;6(2). 